\title{
Puntos de partida. Creación, historia sagrada y esquemas temporales en la Hispania visigoda
}

\author{
Points of departure. Creation, sacred history and temporal frameworks \\ in Visigothic Spain
}

(4) Dolores Castro

IMHICIHU, CONICET, Universidad Nacional de General Sarmiento, Argentina

Fecha de recepción: Agosto 2018. Fecha de aceptación: Octubre 2018.

\begin{abstract}
Resumen
Este artículo analiza el papel del obispo en la elaboración, adaptación y actualización de los esquemas temporales y relatos sobre los orígenes del mundo y del hombre, que, basados en la tradición bíblico-patrística, ofrecieron un marco cristiano de referencia e identidad. El trabajo aborda la tarea de la jerarquía eclesiástica visigoda, principalmente de los obispos Isidoro de Sevilla, Ildefonso de Toledo y Julián de Toledo, y examina las estrategias y procedimientos diversos que forjaron, adaptaron y utilizaron para enseñar la verdadera doctrina y afirmar la unidad de un reino que se reconocía a sí mismo ocupando una posición destacada dentro de la cristiandad.

A partir de un trabajo activo sobre el material bíblico y patrístico, los obispos visigodos al mismo tiempo que enlazaban el presente con la historia sagrada, inscribiendo a la gens Gothorum dentro de un esquema de parámetros universales, se afirmaban como las voces autorizadas para interpretar y enseñar el mensaje revelado.
\end{abstract}

\begin{abstract}
This article studies the role of the bishop in the elaboration and adaptation of temporal models and origin accounts, which, based on the biblical and Patristic tradition, helped to build a Christian framework of reference and identity. The present study addresses the task of the Visigothic ecclesiastical hierarchy, with particular focus on the works of bishops Isidore of Seville, Ildefonsus of Toledo and Julian of Toledo, and examines the different strategies and procedures forged, adapted and used by them in order to teach the true doctrine and assert the unity of a kingdom that thought of itself as occupying a prominent position within Christianity.
\end{abstract}

By working actively on biblical and patristic material, Visigothic bishops strived to link the present with sacred history, inscribing the gens Gothorum within a scheme of universal parameters, and presented themselves as the authorized voices to interpret and teach the revealed message.
Palabras clave

Poder episcopal Reino visigodo Creación

\section{Keywords}

Episcopal power Visigothic kingdom Creation 
1. Esta perspectiva anida principalmente en el Timeo de Platón en donde la creación es atribuida a un demiurgo que modela el mundo a partir de una materia ya existente, de acuerdo a las Ideas eternas, consideradas, a su vez, exteriores al creador. Acerca de la interpretación del Timeo en la temprana Edad Media, véase: Otten (2005: 225-243).

2. Véase, por ejemplo, Kannengiesser (2004), Vannier (2011), Evans, Lohr y Petersen (2012) y Grypeou y Spurling (2013). En este último se estudian potenciales encuentros exegéticos entre las tradiciones cristiana y rabínica en la Antigüedad tardía a propósito del Génesis y sus principales núcleos narrativos.
Las palabras que dan comienzo al Credo, pieza central de la liturgia católica, evocan directamente el relato de la creación: creemos en un solo Dios Padre todopoderoso, creador de todo lo invisible y lo visible. Con esta afirmación los primeros concilios ecuménicos, Nicea (325) y Constantinopla (381), pusieron de manifiesto la centralidad de la teología de la creación en un contexto en el cual la identidad cristiana se encontraba en pleno proceso de definición. Ante las diversas corrientes que circulaban en la época, los Padres de la Iglesia debieron afianzar la nueva doctrina y precisar límites en la interpretación del mensaje revelado.

Durante los siglos II y III, la noción de la creación se había convertido en terreno de disputa entre diferentes líneas interpretativas. Fue Ireneo de Lyon quien, con el fin de refutar las creencias gnósticas, en particular la vertiente valentiniana, elaboró en su Aduersus Haereses una de las primeras síntesis teológicas construidas a partir del relato de la creación (v. Chaieb, 2011: 9-24): el mundo había sido creado por un solo Dios, único y omnipotente, ex nihilo, es decir, sin intermediario alguno ni materia preexistente, a través de un acto de libre voluntad, producto de la bondad y el amor del Dios creador. Se fue forjando, de esta forma, un relato propio distanciado de otras posturas difundidas en la época como la griega-platónica ${ }^{1}$ o la gnóstica en sus múltiples ramificaciones. En este contexto se definieron los principales lineamientos teológicos cristianos acerca de la creación de las cosas visibles e invisibles que, además, llevaban consigo una determinada concepción del hombre y de la relación de este último con su creador y el mundo creado.

La creación del mundo instalaba múltiples interrogantes y, desde antiguo, el Génesis, primer libro del Antiguo Testamento, había recibido especial atención entre los expertos, tanto judíos como cristianos, interesados en desandar la multiplicidad de aspectos (teológicos, antropológicos, ontológicos y soteriológicos) contenidos en la revelación. ${ }^{2}$ La interpretación de la herencia veterotestamentaria en general, y la del Génesis en particular, conllevó la elaboración y definición de un relato autoritativo único que suponía la configuración de una antropología y una soteriología determinadas, ambas íntimamente relacionadas con Cristo y su papel en la economía de la salvación. En torno de la creación, pues, anidaron inquietudes, incertidumbres y enigmas que prevalecieron en el tiempo y exigieron a su turno renovadas respuestas en renovados contextos y escenarios.

Las páginas que siguen proponen examinar la elaboración y actualización de los relatos sobre los orígenes y de los esquemas temporales disponibles para explicar el devenir del mundo y del hombre en la Hispania del siglo VII. Más específicamente, el trabajo analiza el papel desempeñado por la jerarquía episcopal y sus principales representantes -Isidoro de Sevilla (c. 556-636), Ildefonso de Toledo (607-667) y Julián de Toledo (c. 642-690)- en la construcción de un marco específicamente cristiano en el cual inscribir a un reino que se reconocía a sí mismo como un locus privilegiado de la ortodoxia, ocupando una destacada posición dentro de la cristiandad. En esta tarea, los obispos visigodos entrelazaron componentes bíblicos y patrísticos, configuraron relatos diversos al mismo tiempo que se dispusieron a enseñar la verdadera doctrina afirmándose como los principales vectores del mensaje sagrado. A través de una variedad de técnicas, métodos y marcos genéricos, estas personalidades destacadas del escenario visigodo adaptaron y transmitieron un contenido bíblico determinado: configuraron ejemplos, modelos, argumentos y marcos de acción para un presente que era entendido dentro del contexto más amplio de una historia universal de la redención.

Ahora bien, la voluntad de los doctores de Hispania de mostrar su ortodoxia en relación al dogma niceno adoptado oficialmente en el territorio godo tan solo unas décadas atrás (589), impulsó la producción de textos pastorales, doctrinales e históricos a 
partir de los cuales se buscó definir y consolidar la nueva identidad del reino católico de Toledo y de su gens. En esta misión las Sagradas Escrituras constituyeron una pieza fundamental en la afirmación de la unidad política y religiosa teóricamente alcanzada y en la elaboración de marcos de identificación que apuntaron a forjar una percepción colectiva de matriz cristiano-bíblica. Empero, para llevar la doctrina a todos los súbditos era necesario un clero instruido en los misterios sagrados, capaz de discernir entre la verdadera fe, y la ilusión y la perfidia. En este sentido, la pregunta por el origen del mundo y del hombre cargaba con una diversidad de lecturas, mitos y relatos de distinta procedencia y carácter. En consecuencia, proporcionar una respuesta específicamente cristiana despertó el interés de los obispos visigodos, quienes, con mayor o menor grado de intensidad, se volcaron a enseñar al clero y por mediación de este a la comunidad en general, la verdadera doctrina, contraponiendo los postulados cristianos a los falsos y perniciosos. Dentro de este último conjunto, la 'cuestión judía' preocupó especialmente a la jerarquía eclesiástica, en particular a los obispos Isidoro de Sevilla, Ildefonso y Julián de Toledo. En líneas generales, estos prelados se preocuparon por marcar en sus enseñanzas aquello que diferenciaba, en materia doctrinal y ritual, al cristianismo del judaísmo, a la verdadera interpretación del mensaje revelado de la 'impía ceguera' atribuida, desde tiempos patrísticos, al antiguo pueblo de Israel. Por lo tanto, un tópico tan espinoso como la creación -por nombrar tan solo un ejemplo- debía ser leído desde una perspectiva cristiana que los obispos retoman, organizan y apuntalan para ser transmitida a otros miembros del clero y a los sectores esclarecidos de la aristocracia e indirectamente también a los súbditos cristianos del reino católico de Toledo. Los máximos representantes de la iglesia visigoda, erigidos en protectores de la ortodoxia desde 589, al mismo tiempo que preparaban al pueblo visigodo para asumir un papel protagónico en la historia universal de la salvación, se afirmaban local y regionalmente al autorizar, definir y transmitir determinados saberes y conocimientos, al discernir las interpretaciones verdaderas de las falsas -estas últimas ineficaces para alcanzar el destino salvífico- y al articular en su papel de portavoces de la sabiduría bíblica la interpretación del mensaje revelado.

\section{Elección divina: derroteros y advertencias}

Múltiples relatos y esquemas temporales fueron elaborados a lo largo de la historia para explicar el origen y el devenir del mundo y del hombre, dotar de sentido a la existencia de las cosas animadas e inanimadas, en fin, para elucidar el origen del cielo y de la tierra, de la naturaleza y de la humanidad.

La primera narración del Génesis (Gen 1,1-2,4a) 3 describe los seis días de la creación, es decir, despliega la obra creadora de Dios, comenzando con la creación de la luz en el primer día y culminando con la del hombre en el sexto. El interés en este relato conoció un período de auge con los antiguos Padres cristianos, inspirados a su vez en la exégesis judía, especialmente en Filón de Alejandría. Tanto la tradición griega (Orígenes; Basilio; Gregorio de Nisa) como latina 4 (Ambrosio de Milán; Agustín de Hipona) demostraron una particular inclinación a explicar el Hexamerón y con ese objetivo elaboraron un conjunto heterogéneo de obras que sirvieron de base para la reflexión de futuros autores. ${ }^{5}$ A la hora de remitirse a la creación, a los orígenes del mundo y del hombre, los obispos de la Hispania visigoda contaban con una extensa tradición detrás, un conjunto de marcos interpretativos disponibles para abordar cuestiones vinculadas al origen del mundo y de la humanidad.

Ahora bien, el relato de los seis días es retomado por Isidoro de Sevilla en distintas oportunidades y también, llegando al final del período estudiado, por el obispo Julián
3. La composición del primer libro del Pentateuco ha dado lugar a intensos debates historiográficos. Un repaso de las distintas perspectivas en torno de esta problemática en: Gertz, Schmid y Witte (2002).

4. Es preciso anotar en este punto que el interés en el primer libro del Pentateuco no se limitó a las tradiciones griega y latina; como destaca Louth comentarios del Génesis se registran también en lengua siríaca. Cf. Louth (2012: 561-578).

5. De acuerdo con Kannengiesser, los primeros tratamientos cristianos sobre el Génesis se concentraron específicamente en el relato de los seis días de la creación: "These works, Hexaemera, could be devotional, in praise of and wonder at God's creative majesty, or technical in explanation of the procedure of God's creative act. They were written by Melito of Sardis, Rhodo, Candidus, Apion, Maximus, Hippolytus, Victorinus of Pettau, Severian of Gabala, Basil of Caesarea, Gregory of Nyssa, Ambrose, and John Philoponos". En Kannengiesser (2004: 278). Véase, también, Hamman (1968: 1-23), y Lewis (1989: 433-455). 
6. Acerca de la noción de Israel como pueblo elegido, véase: Powis Smith (1929: 73-82), Brett (2002), Lieu (2004) y Buell (2005).
7. La autora analiza la recepción de esta noción en el reino franco, y propone una elaboración más tardía de la esbozada tradicionalmente. Acerca de la retórica de la elección en este mismo pueblo, véase también Heydemann y Pohl (2016: 13-31). de Toledo. En estos casos, y especialmente en el hispalense, la creación constituye el punto de partida a través del cual el presente visigodo se inscribe en una historia sagrada dividida a su vez en seis edades. Situar a los godos dentro de este esquema temporal -que reconocía en la creación el comienzo de la primera edad-implicaba, además, definir el papel que aquel pueblo estaba destinado a cumplir dentro del orden divinamente creado, es decir, dentro del plan de salvación diseñado por la divinidad. En cambio, como se observará más adelante, Ildefonso de Toledo se inclinaba por un esquema de base paulina, una sucesión de etapas cronológicas que encuadraban el devenir de la humanidad hasta el advenimiento del reino futuro en tres momentos: antes de la ley, después de la ley y la edad del espíritu. La introducción de este derrotero permitía al toledano cargar nuevamente las tintas en la separación entre el viejo y el nuevo Israel, en la responsabilidad que conllevaba el papel asumido en la nueva alianza.

En el Antiguo Testamento Israel se constituye en pueblo elegido gracias a la elección divina. ${ }^{6}$ Dios elige (acto voluntario) al pueblo hebreo entre todas las naciones que ha creado y entabla con él una relación pactual y única que se despliega en un mundo que también ha sido deseado y creado por la divinidad. Como se lee en el Pentateuco, esta alianza entre Dios e Israel, sellada a través de una serie de pactos, concedía a los hebreos una posición privilegiada frente al resto de las naciones y al mismo tiempo esperaba de aquel pueblo obediencia y fidelidad.

A partir del primer cristianismo, sin embargo, la noción de 'pueblo elegido' conoce una nueva elaboración, en particular, en los escritos del Nuevo Testamento, según la cual a partir de la Encarnación es la ecclesia el cuerpo llamado a ocupar la posición anteriormente consagrada a los judíos. Por lo tanto, es dentro de esta ecclesia donde la elite eclesiástica situará al reino visigodo de Toledo, a su rey y al conjunto de su pueblo.

Es preciso detenernos en este punto y preguntarnos cómo la idea de la elección divina orbitó en la Hispania del siglo VII, más específicamente en las obras de los obispos aquí analizados. Como advirtió Garrison, ${ }^{7}$ la noción de pueblo elegido invita a cierta cautela en el análisis, pues no responde a un único significado o función. Estamos ante una idea extremadamente poderosa que reveló a lo largo de la historia usos y apropiaciones diversas, en especial desde la Reforma protestante en adelante. En este sentido, como destaca la autora, esta noción no solo otorga una nueva identidad a un grupo, en la medida en que une su historia e identidad con un pasado antiguo y sagrado, sino que conlleva, además, el arraigo de una creencia que entiende el presente como recreación de la relación pactual con los elegidos, pero también como cumplimiento de palabras y eventos bíblicos (Garrison, 2000: 177).

La autora despliega más advertencias: por un lado, apunta a las características inherentes al procedimiento tipológico. Advierte prudentemente que no toda alusión a la historia del Antiguo Testamento evoca necesariamente la noción de la elección, ni esta última indica en todos los casos la autorrepresentación de un pueblo como el Nuevo Israel. En cambio, sostiene Garrison, la tipología del Antiguo Testamento presenta una variedad de funciones y mecanismos: formula metáforas, deseos o esperanzas, describe las cosas reales o bien sugiere un modo o deber ser determinado (cf. Garrison, 2000: 118). Por lo tanto, considerando esta precaución, debemos anotar que esta conexión en el caso visigodo transita sinuosos derroteros, no es homogénea y mucho menos explícita. Con esto quiero decir que el análisis no es lineal y debemos mirar en los intersticios del discurso. Tampoco -última advertencia- las fuentes se alimentan exclusivamente del sustrato bíblico.

Ahora bien, estas observaciones, lejos de paralizar la investigación, invitan aún más a indagar la recepción de los modelos del Antiguo Testamento en la Hispania visigoda. 
A los ojos de los obispos, desde una perspectiva teológica, Israel era -y así lo afirmaba principalmente el Nuevo Testamento- toda la ecclesia: la totalidad de los cristianos eran ahora considerados parte integrante del pueblo de Dios. Tal como señalaba Isidoro de Sevilla en sus Sententiae: "Sancta ecclesia ideo dicitur catholica, pro eo quod uniuersaliter per omnem sit mundum diffusa. Nam hereticorum ecclesiae in partibus mundi coartantur; haec uero in toto orbe diffusa expanditur, Paulo adtestante apostolo: Gratias, inquit, ago Deo pro omnibus, quia fides uestra adnuntiatur in uniuerso mundo". 8

Es Ildefonso de Toledo quien, en De cognitione baptismi, introduce el conocido pasaje de la primera epístola petrina $(1 \mathrm{Pe} 2,9)^{9}$ en el que el Apóstol recoge la terminología electiva del Antiguo Testamento:

\begin{abstract}
Hinc eodem exorcizationis tempore bene in conuentu ecclesiae, antequam exorcismi dicantur, profertur lectio Isaiae prophetae in qua dicitur: Numquid tolletur a forte praeda, aut quod captum fuerit a robusto saluum esse poterit? Quia haec dicit Dominus: Equidem et captiuitas a forte tolletur, et quod ablatum fuerit a robusto, saluabitur. Item Petri ad gentes: Vos autem, genus electum, regale sacerdotium, gens sancta, populus adquisitionis, ut uirtutes annuntietis eius, qui de tenebris uocauit uos in admirabile lumen suum. Marci quoque euangelistae quae huius effetationis reuelat sacramentum, quae superius et prolata est et disserta, uidelicet ut uirtus Dei per uictoriam crucis praedam humani generis a fortitudine diaboli tollens, faciat genus electum per regenerationis donum, regale quoque sacerdotium per dominium dictionum et oblationem innocentiae atque contriti spiritus sacrificium, infundens illi auditum oboedientiae praeceptorum et dans ei rectae fidei loquellam atque suae gloriae hymnum. ${ }^{10}$
\end{abstract}

En este fragmento, citado in extenso, se observa uno de los principales usos de 1 Pe 2,9 a lo largo del período: un uso que vincula el lenguaje de la elección con el bautismo de todos los cristianos. No es de extrañar la inclusión de este pasaje en una obra dedicada al tratamiento del principal rito cristiano de iniciación y pertenencia. Asimismo, se hace énfasis en la salvación alcanzada a través del bautismo y la responsabilidad que conlleva integrar, una vez atravesadas las aguas, el cuerpo eclesiástico. Este ejemplo, por lo tanto, exhibe el carácter universal del mensaje de Pedro, un mensaje que iba dirigido, con toda la fuerza profética y evangélica, a todos los cristianos por igual.

Además de este uso, fundamental en el primer cristianismo, es posible advertir otras implicancias del lenguaje de la elección. La elite episcopal del reino de Toledo construyó apelando a distintas tradiciones y recursos una posición privilegiada para los visigodos dentro del plan divino. A través de la tipología del Antiguo Testamento, principalmente, era posible activar una cadena de relaciones y significados que apenas evocados comenzaban a jugar en el presente incluso sin la necesidad de explicitar nombres o acontecimientos específicos.

Como bien destacó Heydemann, la Biblia -y especialmente el Antiguo Testamentocumplió un papel fundamental en la conceptualización de la etnicidad y la religión como factores de cohesión social e integración política (Heydemann, 2013: 148). En este sentido, virtudes, destrezas y prácticas -pero también riesgos y perjuicios- veterotestamentarios ofrecían puntos de identificación posibles, rendijas a través de las cuales el pasado bíblico emergía arrojando nueva luz hacia el presente. Las obras visigodas apelan constantemente al universo del antiguo Israel principalmente en contextos de exhortación moral; Israel es modelo pero también advertencia y límite.

Es Isidoro de Sevilla quien emprende con mayor interés esta tarea que combina distintas estrategias, géneros y tradiciones -a veces convergentes, otras en conflictopara dotar a los godos de un lugar preferencial dentro de la historia de la salvación.
8. Isidoro de Sevilla, Sententiae I, 16, 6a. La misma idea recoge Ildefonso en De cogn. bapt., LXXIII. Como el obispo de Hispalis, también el de Toledo contrapone la universalidad de la ecclesia a la dispersión y regionalización de los herejes.

9. Acerca del uso de este pasaje, véase Heydemann y Pohl (2016: 16). De acuerdo con los autores, 1 Pe 2,9 era utilizado frecuentemente en los desarrollos exegéticos que apuntalaban la idea de un pacto cristiano mediante el cual los judíos eran reemplazados en su papel de pueblo elegido. Esta apropiación, como indican Heydemann y Pohl, implicaba desarticular el particularismo étnico, el origen común, y favorecer, en cambio, una visión de comunidad de alcance universal. Por lo tanto, en marcado contraste con el Antiguo Testamento, la promesa de elección procedente del Nuevo hacía de la lealtad (fides) a Cristo y al evangelio el criterio de pertenencia principal.

10. Ildefonso de Toledo, De cogn. bapt., XXIX. 
11. De acuerdo con Wood, Isidoro, en sus escritos históricos, no solo situó a los visigodos dentro de una historia universal en la que gozaban de un lugar privilegiado, sino que además optó por denigrar a sus competidores, al demostrar, por ejemplo, que tanto judíos como romanos habían perdido todo derecho a reclamar un status religioso de importancia. 12. Entre muchas otras contribuciones en la temática, véase: Haldon (1990),

Dagron (1996) y Bonfil, Irshai, Stroumsa y Talgam (2012).

13. De acuerdo con Fontaine esta obra habría sido redactada en dos versiones. Cf. Fontaine (2000). En este trabajo seguimos la cronología propuesta por J.C. Martín, quien sitúa la primera redacción alrededor de 615/616, durante el reinado de Sisebuto, y la segunda en 626. Cf. Martín (2001: 199-239). Otra versión abreviada habría sido finalizada hacia 626 y publicada como parte de las Etymologiae en 627-8 (cf. Wood, 2012). Por su parte, Aldama en su cronología general de obras isidorianas sitúa la Crónica entre las Sententiae y el De fide catholica (cf. de Aldama, 1936: 88).

15. Entre ellos: Martín (2001: 199-239), Merrills (2005) Koon y Wood (2008).

14. De acuerdo con Aldama (de Aldama, 1936: 62), dos indicaciones de carácter histórico habrían servido para determinar la redacción doble de esta obra: (continúa en página 58)

16. Koon y Wood (2008: 4): “...Isidore was active and reflective in his use of a range of late antique historical and chronographic sources when writing

the Chronica Maiora. This active engagement is indicative of Isidore's involvement in and desire to influence contemporary political and religious developments". En el mismo sentido,

Reydellet (1970: 377): "il [lsidore] introduit dans sa Chronique une vision originale de l'histoire non pas comme oeuvre littéraire ou comme partie d'une culture, mais comme réalité concrète dévoilant le destin de l'humanité".

17. Martín (2001: 206)

18. También la Historia Gothorum presenta dos redacciones: la primera en el año 621 y la segunda en el 626. Seguimos en este punto a J.C. Martín. Según Aldama, en cambio, la Historia habría sido elaborada en torno al 624 (cf. de Aldama, 1936: 88).

19. Cf. Wood (op. cit.: 94). Como señala Wood, a partir de la recuperación de antiguos referentes de la cronografía Isidoro no solo se inscribía dentro de aquella tradición, sino que consolidaba su papel como experto en la temática -la historia universal-

al enaltecer su autoridad como teórico de la escritura de la historia.
Esta intervención activa de Isidoro ha sido estudiada por Wood (2012; 2013: 125-168), relacionada principalmente con sus escritos históricos (Wood, 2012: 133), ${ }^{11}$ en particular con los Chronica (y sus diversas redacciones) y la Historia Gothorum (cf. Wood, 2012: 148).

En el marco de la conversión al catolicismo en 589, el concilio III de Toledo había celebrado la unidad del reino visigodo bajo una sola fe asumiendo un papel especial en la historia de la salvación. En esta tarea, que implicaba elevar al pueblo godo a una posición privilegiada dentro de la ecclesia, el episcopado asumió una función de importancia decisiva en la medida en que debió definir el lugar reservado para el reino godo dentro del orden deseado y creado por la divinidad. Recordemos que esta misma función ya era asumida por el Imperio. ${ }^{12}$ Como destacaron los especialistas, este último se veía a sí mismo como el nuevo pueblo elegido, un nuevo Israel, y a su capital Constantinopla como una nueva Sion. Los emperadores bizantinos eran la actualización de los modelos del Antiguo Testamento: no solo considerados elegidos y protegidos por Dios, sino también cumpliendo un significativo papel en la economía de la salvación. Por lo tanto, proponerse en el extremo occidente como un nuevo baluarte de la ortodoxia, como un pueblo ocupando una posición preferencial en un mundo cristiano, implicaba, por lo menos, añadir una mayor complejidad al escenario articulado por la corte imperial y el patriarcado de Constantinopla.

En este proceso, los obispos del reino de Toledo encararon un trabajo multifacético, al activar procedimientos hermenéuticos y reelaborar tópicos bíblicos destinados a enlazar el presente visigodo con la historia sagrada narrada en las Escrituras. En este sentido, discurso histórico y discurso exegético se aproximan en la construcción de una visión determinada del pasado y a partir de este de la propia actualidad visigoda (cf. Corradini, 2003: 269-321; Wood, 2012).

\section{Isidoro de Sevilla y los seis días de la creación}

Uno de los primeros aportes en este sentido fue la Crónica de Isidoro de Sevilla. ${ }^{13}$ En este breve escrito el obispo desarrollaba una versión propia de la historia universal de la salvación que se extendía desde la creación hasta el siglo VII. ${ }^{14}$ En aquel entonces, la conocida Crónica de Eusebio, completada y traducida al latín por Jerónimo, había operado como el modelo narrativo por excelencia de relatos historiográficos de esta índole. Sin embargo, como bien han destacado diversos especialistas, ${ }^{15}$ Isidoro no reproducía estrictamente los modelos de antaño sino que combinaba y adaptaba distintos elementos para dar forma a una auténtica obra de circunstancia. ${ }^{16}$ Según Martín, estaríamos ante "un manual abreviado de historia universal" concebido como "una crónica original producto de los medios intelectuales visigodos, marcando con ello la independencia política y cultural del reino de Toledo frente a las crónicas precedentes, construidas en su mayoría sobre una concepción romana e imperial de la historia del mundo". ${ }^{17}$ En este sentido, afirma el autor que la Crónica, como también la Historia Gothorum, ${ }^{18}$ formaba parte de un proyecto de mayor alcance cuyo objetivo consistía en introducir y destacar al reino de Toledo en el marco más extenso de la cristiandad. En esta operación Isidoro necesitaba, por un lado, activar los modelos historiográficos precedentes ${ }^{19}$-montarse sobre una tradición y utilizarla según sus propósitos- y construir una novedad, una obra que dejara atrás viejos esquemas que no contemplaban la actualidad de la Hispania del siglo VII. La Crónica afirmaba así la identidad de un reino, de una unidad dotada de un pasado cristiano que comenzaba con el relato de la creación, se encuadraba en las narrativas bíblicas hasta desembocar en las peripecias godas en tierras peninsulares. En las obras históricas, la exaltación de las victorias bélicas 
y la afirmación de la ocupación legítima del territorio hispánico, otrora romano, sumado a las alabanzas por su carácter devoto y ortodoxo (en contraposición a la imagen del pasado romano) constituyeron algunos de los basamentos (cf. Martín, 2001: 199-239; Wood, 2012) sobre los cuales el hispalense construyó un pasado y un presente y, por qué no, también un futuro para el reino católico de Toledo. En este sentido, no podemos dejar de mencionar brevemente el fragmento que antecede a la Historia Gothorum, conocido como Laus Spaniae o De laude Spaniae. ${ }^{20}$ En esta sección, Isidoro en un tono retórico elevado, elaboraba una glorificación de Hispania, madre de príncipes y pueblos, exaltando la geografía de "la más ilustre porción de la tierra", la fertilidad y la abundancia de sus campos, montes y ríos. Más específicamente, celebraba Isidoro la tierra donde florecía la gens Gothorum, luego del triunfo sobre Roma, antigua ocupante de la península. ${ }^{21}$ A pesar de su reducida extensión, esta alabanza tenía mucho por decir, pues en ella se configuraba la posición privilegiada que Hispania y el reino visigodo de Toledo estaban llamados a ocupar dentro del orbe cristiano. Hispania se revestía de una centralidad única entre las tierras que se extendían ab occiduo usque ad Indos. ${ }^{22}$ Como bien señaló Martin, "la gens des Goths est présentée par Isidore d'une part comme un groupe "viril", violent, caractérisé par son emploi de la force armée, d'autre part comme le sujet d'une alliance avec Dieu" (Martin, 2008: 78).

Ahora bien, nuevamente en su Crónica, Isidoro de Sevilla, diferenciándose de antecedentes locales como la obra de Juan de Bíclaro, por primera vez situaba a la Hispania goda dentro de un esquema construido a partir de parámetros universales. Asimismo, la entrada del reino de Toledo en un diseño de tales características sin duda reflejaba el papel protagónico que las elites visigodas creían ocupar dentro del mismo. Por lo tanto, la consolidación del regnum Gothorum en este escenario cristiano requería activar un pasado bíblico que al remontarse a la actividad creadora de Dios destacase a los godos como los depositarios privilegiados de la ortodoxia.

Poco tiempo después de redactada su Crónica, una vez diseñado a grandes rasgos el esquema temporal del mundo y definidas sus edades a partir de personalidades y eventos bíblicos, Isidoro acercaba la lupa y emprendía, ahora sí, una historia específica del pueblo godo, de sus victorias y de sus reyes, en ese otro escrito, profundamente vinculado con el primero, conocido como Historia Gothorum. En este último, el obispo hispalense, además de colmar a los godos con alabanzas y glorificaciones, realzaba su protagonismo, su condición de pueblo elegido y heredero del reino celeste. ${ }^{23}$ Incluso este vínculo entre los godos y la divinidad, entre un pueblo y su destino escatológico, podía advertirse desde la etimología, pues Isidoro dotaba a los primeros de un origen antiquísimo que se remontaba a Magog, ${ }^{24}$ hijo de Jafet. ${ }^{25}$ Como explicaba el obispo en la redacción larga de su Historia, 'Gog y Magog' eran definidos como tectum, símbolo de fortaleza asociado en la reflexión isidoriana a los orígenes del pueblo godo.

Retomemos ahora el análisis de la Crónica, es decir, el marco cristiano-universal en el que Isidoro había apuntado al reino visigodo de Toledo. Este breve escrito comenzaba con la creación del mundo sintetizada en el esquema de los seis días: "Sex diebus rerum omnium creaturam deus formauit: primo die condidit lucem, secundo firmamentum caeli, tertio speciem maris et terrae, quarto sidera, quinto pisces et uolucres, sexto bestias atque iumenta, nouissime ad similitudinem suam hominem primum Adam". ${ }^{26}$ El relato de la creación opera aquí como un punto de partida, es decir, como el inicio de una historia que avanzaba desde la creación divina y las genealogías bíblicas, atravesaba el imperio romano y convergía en el presente de quien escribía: 600 años después de la muerte de Cristo. El reino visigodo de Toledo era enlazado de esta forma directamente con el pasado escriturario y cristiano, y se constituía al mismo tiempo en el verdadero heredero del legado bíblico y romano.
20. Para un estudio de la tradición manuscrita, autenticidad y posición de la Laus en los códices, véase Rodríguez Alonso (1975: 7-64). Desde identificar en la Laus un carácter netamente nacionalista (Teillet, 1984) hasta, en las antípodas, advertir en ella solamente una alabanza geográfica (Elías de Tejada, 1960: 225-238) o una propaganda regia (Hillgarth, 1970: 261311), fueron múltiples las posturas esbozadas acerca de la significación de aquel fragmento isidoriano.

21. Isidoro de Sevilla, Hist., Laus Spaniae, 26-30: "lure itaque te iam pridem aurea Roma caput gentium concupiuit et licet te sibimet eadem Romulea uirtus primum uictrix desponderit, denuo tamen Gothorum florentissima gens post multiplices in orbe uictorias certatim rapit et amauit, fruiturque hactenus inter regias infulas et opes largas imperii felicitate securas".

22. Isidoro de Sevilla, Hist. 1: “...pulcherrima es, o sacra semperque felix principum gentiumque mater Spania".

23. Cf. Isidoro de Sevilla, Hist. Got., 29.

24. Cf. Isidoro de Sevilla, Hist. Got., 1.

25. De acuerdo con Rodríguez Alonso, en esta interpretación Isidoro "recurre a la autoridad del profeta Ezequiel: et magis de Ezechiele propheta id colligentes. La identificación de los godos con la descendencia de los hijos de Jafet está avalada por una tradición que Isidoro se cuida bien de hacer notar, al repetir un pasaje de Jerónimo del que elimina el carácter de duda que ofrece respecto a dicha identificación" (Rodríguez Alonso, 1975: 32). (continúa en página 58) 26. Isidoro de Sevilla, Chron. I, 3. 
27. Recordemos que Isidoro retoma el esquema agustiniano de las seis edades únicamente en la segunda versión de su Crónica y en Etymologiae, V.

28. Para un tratamiento de la concepción de la historia en Agustín de Hipona, véase: Marrou (1950) y Markus (1970).

29. Según Wood, la distancia entre Isidoro y sus predecesores Eusebio y Jerónimo se debe principalmente al rechazo del hispalense de la ideología proimperial característica de la antigua Crónica (Wood, op. cit.: 101).

30. Isidoro de Sevilla, Etym. V, xxxviii, 5. La traducción es de Barney, Lewis, Beach y Berghof (2006).

31. Isidoro de Sevilla, Etym. V, xxxix, 1: "The first age has the creation of the world as its beginning, for on the first day God, with the name of 'light,' created the angels; on the second, with the name of the 'firmament,' the heavens; on the third, with the name of 'division,' the appearance of waters and the earth; on the fourth, the luminaries of the sky; on the fifth, the living creatures from the waters; on the sixth, the living creatures from the earth and the human being, whom he called Adam".

32. Sobre este tema, véase Lewis (1989: 433-455).
El desarrollo de la actividad creadora de Dios en seis días aparece también en la segunda versión de la Crónica inaugurando el esquema de las seis edades. ${ }^{27}$ Este marco, sin embargo, no era original de Isidoro: el hispalense lo retoma principalmente de Agustín, ${ }^{28}$ mas introduce algunas modificaciones respecto de su antecesor. En primer lugar, como anotamos, Isidoro comienza su relato con la creación, mientras que Agustín, en cambio, sitúa el inicio de la primera edad en Adán. En segundo lugar, los separadores que introduce entre las edades no coinciden en todos los casos ni con el modelo agustiniano esbozado en De ciuitate Dei ni tampoco con el relato cronológico propuesto en la crónica de Eusebio y Jerónimo. ${ }^{29}$ De esta forma, Isidoro se apropiaba del discurso bíblico-patrístico, de las autoridades del pasado, y lo adaptaba a su tiempo para enmarcar la instauración del reino godo en Hispania dentro de una historia sagrada global que reconocía su origen en la creación y avanzaba hacia el Juicio Final. Por consiguiente, en la reflexión isidoriana el esquema de las edades no constituía solo el marco de una historia religiosa, sino de una historia universal en la cual el elemento cristiano y el profano conformaban una unidad indisoluble.

Ahora bien, la Crónica no es la única obra en la que el hispalense hace uso de este esquema particular. En ese otro epítome conocido como Chronica minora, situado en el Libro V de las Etymologiae, introduce también la periodización heredada de Agustín:

The term 'age' properly is used in two ways: either as an age of a human - as infancy, youth, old age - or as an age of the world, whose first age is from Adam to Noah; second from Noah to Abraham; third from Abraham to David; fourth from David to the exile of Judah to Babylon; fifth from then, [the Babylonian captivity], to the advent of our Savior in the flesh; sixth, which is now under way, to when the world itself comes to an end. ${ }^{30}$

A continuación, el hispalense -como en la Crónica- desarrolla de forma breve el contenido de esta división cronológica. Si bien sitúa el inicio de la primera edad en Adán, destaca que esta última contenía en su comienzo la creación. ${ }^{31}$ Una vez más, sintetizaba Isidoro la actividad creadora de Dios en seis días, aunque sin ofrecer aclaración alguna acerca de cómo entender, si desde un punto de vista literal o espiritual, la semana de la creación. Recordemos que en el pasado la interpretación de los primeros pasajes del Génesis había dado lugar a concepciones consideradas a posteriori erróneas y heréticas desde un punto de vista cristiano, especialmente en el curso del siglo II. ${ }^{32}$ Asimismo, algunos Padres de la Iglesia habían adoptado una concepción de la semana que asimilaba los seis días de la creación con las seis edades del mundo, interpretación que supo adquirir en ocasiones también matices milenaristas. Creemos, por lo tanto, que en la visión isidoriana aparecen combinados dos factores: en primer lugar, la necesidad de presentar de forma breve la creación, como una obra exclusiva de Dios, y articular a partir de allí un esquema de mayor alcance que presentara de forma sucesiva las distintas etapas a través de las cuales había transcurrido el mundo desde aquel punto de inicio hasta el siglo VII. Asimismo, el hispalense transmitía un mensaje fundamental: el mundo tal y como se lo conocía, incluyendo los seres espirituales y materiales, habían sido creados por la divinidad de la nada y sin intermediario. De esta forma también Isidoro hacía coincidir en su segunda versión de la Crónica el comienzo del mundo con la creación tal como se leía en el primer libro del Pentateuco. En segundo lugar, al no introducir, al menos en esta obra, la correspondencia entre días (de la creación) y edades (del mundo) Isidoro ofrecía una lectura de la obra creadora que, al sintetizar los conocimientos elementales de la misma, no entraba en interpretaciones complejas y evitaba, de aquel modo, confusiones que podían eventualmente derivar en opiniones erróneas de carácter milenarista o mesiánico. En esta línea, como citamos más arriba, Isidoro complementaba su exposición de las seis edades del mundo, aclarando que la sexta edad se encontraba en pleno acontecer. 
Nuevamente el relato de los seis días de la creación atrae la atención del obispo de Hispalis, esta vez en su Expositio in vetus Testamentum..$^{33}$ En continuidad con la tradición, en especial en su vertiente agustiniana, pero lejos del contexto polémico y apologético que sumergió a los antiguos Padres, el obispo no se detiene exhaustivamente en puntos doctrinales ya resueltos; su exposición, por lo tanto, no aborda la totalidad de los pasajes del primer libro del Pentateuco. Como en otras obras de cuño isidoriano, el enfoque adoptado es el alegórico-espiritual, en detrimento de una comprensión exclusivamente literal del contenido bíblico. Desde esta perspectiva, el relato de los seis días no debía ser entendido según la letra: en cambio, el hispalense enseñaba, siguiendo de cerca la obra de Agustín, su significado simbólico. En esta lectura, pues, la creación de la luz prima die se entiende como símbolo de la luz de la fe, de la separación entre los justos, el día, y los pecadores, la noche. ${ }^{34}$ En este sentido, la luz es símbolo del bien y de la santidad. En el segundo día, continúa el hispalense, creó Dios el firmamento, "solidamentum sanctarum scripturarum",; el tercero las aguas, homines infideles, y las tierras áridas (pueblo sediento del agua de la fe); el cuarto, las luminarias "...id est, euangelistae et doctores, scripturae sanctae disputando cohaerentes, et omnibus inferioribus lumen sapientiae ministrantes". ${ }^{36} \mathrm{El}$ quinto día fue el turno de los animales del agua, homines renouati in uitam per baptismi sacramentum, y las aves del cielo, "id est, sanctae animae ad superna uolantes",; por último, en el sexto día creó Dios a los animales salvajes y a las bestias (símbolo de los hombres soberbios), a los animales domésticos (pecora), es decir, a los fieles que viven una vida simple, y también a las serpientes inofensivas, hombres santos que distinguen entre lo bueno y lo malo. Por último, formó Dios al hombre a su imagen y semejanza: al hombre perfecto que obra la justicia. ${ }^{38}$ Recordemos que, a diferencia de los escritos isidorianos analizados anteriormente, en esta obra Isidoro se había propuesto la elaboración de un comentario exegético sobre el Antiguo Testamento y, por lo tanto, estaba dirigido a un público más especializado y reducido, un público que debía estar preparado para alcanzar niveles de comprensión espiritual y moral más profundos y elevados. La exégesis visigoda no se concreta en un tratado específico sino que, en la medida que busca aleccionar a un público letrado lo más amplio posible, se pone al servicio de géneros literarios diversos.

Ahora bien, estas dos formas de interpretar el Hexamerón coexisten en el pensamiento isidoriano, pues el texto sagrado admitía más de una lectura posible. Entre la letra y el espíritu, el relato de los seis días era interpretado, por un lado, en sincronía con el presente visigodo, es decir, como el punto de partida de una historia sagrada que tenía inicio en la creación y continuaba hasta los reyes visigodos. Por el otro, el hispalense anotaba en la Expositio in vetus Testamentum ${ }^{39}$ una lectura espiritual del mismo relato: una interpretación simbólica que, inspirada en la reflexión patrística anterior, evitaba los inconvenientes teológicos implícitos en una comprensión literal de la actividad creadora de Dios. En esta última obra, Isidoro privilegiaba una vez más la perspectiva figurativa que inscribía a los fenómenos naturales dentro de un orden específico, creado y deseado por la divinidad, e impartía enseñanzas de carácter moral consideradas indispensables para llevar adelante una vida acorde a los parámetros cristianos. En este sentido, también en Expositio in vetus Testamentum Isidoro introduce el esquema, ya citado en las Etymologiae, de la historia del género humano basado en las seis edades de inspiración agustiniana: la primera de Adán a Noé, la segunda de Noé a Abraham, la tercera hasta David, la cuarta hasta el cautiverio babilónico y la anteúltima hasta Cristo, momento en el que se inicia la sexta y última generación. En este caso, sin embargo, el hispalense sí introduce una correspondencia entre los seis días de la creación y las seis edades o generaciones del mundo. $4^{\circ}$ Desde luego, como mencionamos, Isidoro no había sido el primero en trazar esta continuidad temporal entre el pasado bíblico, el de la alianza entre Dios y el pueblo de Israel, y la llegada de Cristo a este mundo. Otros teólogos cristianos como Eusebio, Jerónimo y Agustín ${ }^{41}$ idearon y utilizaron sistemas cronológicos en sus obras en un intento de dotar a la
33. Distintos títulos se le han adjudicado a esta obra comúnmente conocida gracias a la Patrología Latina como Quaestiones in vetus Testamentum. Gorman, por su parte, propuso el título Expositio in vetus Testamentum debido, en primer lugar, a una mayor afinidad con el objetivo de la obra ("Breui enim expositione succinta non faciunt de prolixitate fastidium") y, en segundo lugar, a la imposibilidad, según el autor, de clasificar la obra de Isidoro dentro del género de quaestioneset-responsiones. Cf. Gorman (2009).

34. Isidoro de Sevilla, Exp. I, I: "lam tunc deus iuxta praescientiae suae gratiam diuisit iustos, id est, filios dei et lucis, a peccatoribus, tamquam a tenebris, istos uocans diem, et illos noctem".

35. Isidoro de Sevilla, Exp. I, 101-102.

36. Isidoro de Sevilla, Exp. I, 126-128.

37. Isidoro de Sevilla, Exp. I, 140-141. 38. Isidoro de Sevilla, Exp. I, I: "Post haec fecit deus hominem ad imaginem suam, perfectum scilicet uirum, qui non quemlibet sanctorum uirorum imitando, sed ipsam ueritatem contemplabiliter intuendo, operatur iustitiam, ut ipsam intellegat, et sequatur, ad cuius imaginem factus est, ueritatem".

39. Si bien la cronología propuesta por Aldama sitúa la elaboración de esta obra hacia el final de la carrera de Isidoro, entre los años 624 y 636 , se trata de una datación sujeta a discusión.

40. Isidoro de Sevilla, Exp. II, 192-204: "Sex diebus consummauit deus omnia opera sua et septimo requieuit. Sex aetatibus humanum genus in hoc saeculo per successions temporum dei opera insigniunt. Quarum prima est ab Adam usque ad Noe, secunda a Noe usque ad Abraham, tertia ab Abraham usque ad Dauid, quarta a Dauid usque ad transmigrationem in Babylonia (continúa en página 58)

41. Harris (2011: 89): “The six ages of Augustine's narrative comprised the biblical story of salvation. God's sole governance of history was the point of the scheme, and Augustine rejected human potential to influence its timing or outcome". 
42. Isidoro de Sevilla, Exp. II, 228-232.

43. Isidoro de Sevilla, Exp. II, 238-239.

44. Isidoro de Sevilla, Exp. I, 78-82.

45. A pesar de no contar con ningún indicio que apunte a datar con precisión la elaboración de la obra, actualmente se la considera propia del período 68o-69o. Cf. Martín (2014: 128). El método de 'preguntas y respuestas' era tan solo una de las estrategias utilizadas por los doctores cristianos en la resolución de problemas exegéticos, especialmente adecuado para ámbitos de instrucción y enseñanza. Su ventaja radicaba, pues, en la posibilidad de transmitir problemas doctrinales de forma clara y concisa, y de enseñar la correcta interpretación de determinados pasajes que podían presentar cierto grado de complejidad si no contaban con una explicación adecuada.

46. La traducción es de J.C. Martín. Julián de Toledo, LA IIII, 6-8: "Sexto die fecit deus hominem ad imaginem suam et sexto saeculo uenit dominus Ihesus Christus ut reformaretur homo ad imaginem dei".

47. Julián de Toledo, LA IIII, 8-15: "Primum enim tempus tamquam primus dies ab Adam usque ad Noe, secundum a Noe usque ad Abraham, inde tertium tempus quasi tertius dies usque ad Dauid, quartum usque ad transmigrationem Babyloniae, quintum usque ad praedicationem lohannis, sextum tempus tamquam sextus dies a lohanne usque in finem. In hoc sexto die Christus de uirgine natus est. Hoc die spiritalis terra fundata est, idest ecclesia".

48. Este interrogante contrapone dos pasajes del Génesis (Gen 2,2 y Gen 2,4) citados por Julián de modo literal: "Cum in Genesi septem primi dies legantur, per quos deus uniuersam creationem perfecit, iuxta quod scriptum est: Et requieuit die septimo ab omni opere suo, quomodo econtra ibi post aliqua unus dies tantum legatur, in quo uniuersa mundana conditio sit creata? Dicit enim: Istae generationes caeli et terrae quando creatae sunt, in die quo fecit dominus deus caelum et terram et omne uirgultum agri uel cetera" (Julián de Toledo, LA I, 1-7).

49. Cf. Gregorio Magno, Mor. in lob 32, 12, 16. historia de una estructura providencial. En el marco de esta obra exegética, el paralelo trazado entre los seis días y las seis edades constituía una prueba más de la relación tipológica entre el Antiguo y el Nuevo Testamento, entre la antigua y la nueva alianza: "Nam sicut in illa sexta die primus homo Adam de limo terrae ad imaginem dei formatus est, sic in ista sexta saeculi aetate secundus Adam, id est, Christus, in carne de Maria uirgine natus est...". ${ }^{2}$ Y, a continuación: "Et quemadmodum in illa die creatur masculus et femina, sic in ista aetate manifestatur Christus et ecclesia". ${ }^{43}$ En este sentido, Isidoro profundizaba una perspectiva cristológica que entendía que así como en el sexto día se había formado al primer hombre, Adán, en la sexta edad había nacido Cristo. De esta forma, el hispalense transmitía una interpretación cristiana de la historia sagrada enlazando a la iglesia y a Cristo, su cabeza, con el relato del Antiguo Testamento. Demostraba una vez más que nada podía comprenderse por fuera de Cristo tal como se anticipaba desde el comienzo de la obra, al comentar los primeros y célebres pasajes del Génesis: "In principio fecit deus caelum et terram (Gen 1,1): Principium Christus est, sicut ipse in euangelio Iudaeis interrogantibus respondit, Ego principium, qui et loquor uobis. In hoc igitur principium fecit deus caelum, id est, spiritales, qui caelestia meditantur et quaerunt. In ipso fecit et carnales, qui terrenum hominem necdum deposuerunt". 44

\section{Desde la urbs regia: el turno de Julián de Toledo}

Ahora bien, como Isidoro de Sevilla, también Julián de Toledo hará uso del esquema basado en las seis edades. En el marco de su De comprobatione sextae aetatis, este obispo, quien escribía desde la capital del reino visigodo, retomaba esta forma de conceptualizar las edades del mundo pero con un objetivo distinto, el de refutar la creencia judía que afirmaba que el mundo aún transitaba la quinta edad y, por lo tanto, la venida del Mesías no había acontecido todavía.

En otro de sus escritos, los Antikeimena o LiberAnticimen, ${ }^{45}$ Julián destina las primeras nueve preguntas a desandar dificultades en torno a la secuencia temporal de la creación. Por ejemplo, se preguntaba el obispo cómo podía entenderse según el Génesis que Dios había creado a los animales y al hombre en el sexto día pero, en cambio, se leía en el salmo 92 que en la víspera del sábado habían sido puestos los 'fundamentos de la tierra'. Para disipar tal confusión Julián retomaba en su respuesta la interpretación que equiparaba los términos 'día' y 'edad'. Desde esta perspectiva, el obispo aseguraba que en "el sexto día hizo Dios al hombre a su imagen y en la sexta edad vino nuestro señor Jesucristo para que el hombre se reformase a imagen de Dios". ${ }^{46}$ A continuación, explicaba: "La primera edad, como si fuese el primer día, fue desde Adán hasta Noé; la segunda, desde Noé hasta Abraham; la tercera edad, como si fuese el tercer día, hasta David; la cuarta, hasta el exilio en Babilonia; la quinta, hasta la predicación de Juan; y la sexta edad, como si fuese el sexto día, se extiende desde Juan hasta el fin de los tiempos. En este sexto día Cristo nació de la Virgen y en ese día fueron puestos los fundamentos de la tierra espiritual, esto es, la Iglesia". 47

En este caso, Julián ponderaba una lectura espiritual que trazaba un paralelo entre los seis días de la creación y las seis edades del mundo desde un punto de vista cristológico y eclesiológico. En rigor, esta interrogatio formaba parte de un conjunto de inquietudes destinadas a recorrer problemas exegéticos derivados de una interpretación estrictamente literal de los seis días. El obispo recogía uno de los principales temas desarrollados otrora por Agustín: cómo entender la creación del tiempo y la creación en el tiempo. Se preguntaba, entonces, Julián cómo es que en el Génesis estaba escrito que la creación se había producido en siete días, pues Dios "descansó al séptimo día de todo su trabajo" (Gen 2,2), y poco después se afirmaba que se llevó a cabo en tan solo un día. ${ }^{48}$ La respuesta, inspirada en Gregorio Magno, ${ }^{49}$ retomaba la dis- 
tinción especie/sustancia para aclarar que la creación se produjo al mismo tiempo en sustancia pero en distinto tiempo en especie: "El origen de todas las cosas se creó a un tiempo, pero no se dio forma a un tiempo a su especie, y así lo que existió a un mismo tiempo por la sustancia de su materia, no se mostró a un mismo tiempo por la sustancia de su forma. En efecto, cuando se dice que a un tiempo se hicieron el cielo y la tierra, se indica que se hizo a un tiempo tanto lo espiritual como lo corporal, que se hizo a un tiempo todo lo que nace del cielo y a un tiempo todo lo que surge de la tierra. Ciertamente, se cuenta que las estrellas se hicieron en el cielo en el cuarto día, pero lo que se mostró al cuarto día en su especie, desde el primer día existió por su creación en la sustancia del cielo. También se dice que el primer día se creó la tierra y se escribe que al tercero se crearon los arbustos y todas las plantas de la tierra. Pero esto que se mostró en su especie al tercer día, ya desde el primer día estuvo creado en la sustancia misma de la tierra de la que nació".50

Por lo tanto, no existía contradicción alguna en afirmar que la tierra, y todo lo contenido en ella, había sido creada en un día y simultáneamente afirmar que, por ejemplo, los arbustos fueron hechos en el día tercero, pues en el primer caso se trata de la sustancia, en el segundo de la especie. La respuesta finalizaba con una referencia literal de las Escrituras: "El que vive eternamente, todo lo creó al mismo tiempo" (Eclo 18,1). ${ }^{51}$

Inquietudes similares revelan las entradas II, III y VI. En esta última interrogatio, Julián se pregunta por qué en las Escrituras se lee que la mujer fue formada del costado de Adán cuando se da a entender en otra parte que esta había sido creada junto con el hombre en el sexto día (Gen 1,27). La respuesta es similar a las anteriores: según la sustancia fueron creados en el mismo día, según la forma, en cambio, Eva fue creada posteriormente a partir de la costilla de Adán. De este modo, ambos relatos de la creación se concilian: se eliminan las aparentes fisuras y se conserva, en el acto, la unidad del texto sagrado. En continuidad con el trabajo encarado por sus antecesores, Julián transmitía una vez más las enseñanzas bíblicas y patrísticas en torno a determinados tópicos que, desde su perspectiva, podían llevar a una comprensión errónea de la doctrina, y perfeccionaba los métodos de instrucción que permitían afianzar las creencias a partir de la repetición de puntos nodales del dogma cristiano. Si bien el toledano ofrecía en el Liber Anticimen efectivamente respuestas elaboradas a partir de fragmentos patrísticos, rasgo característico general de los documentos del período, la selección y el armado de las mismas dejaban entrever algunos indicios acerca de aquello que el obispo deseaba transmitir a su público. Recordemos que al relevar las voces de los antiguos y reunirlas en una única obra el toledano actualizaba tópicos e interrogantes que si bien parecían ya haber sido zanjados, servían para instruir a los sectores jerárquicos de la sociedad visigoda y, al mismo tiempo, enseñar los límites de la interpretación. Las preguntas y respuestas reunidas en el LiberAnticimen constituían una demostración de la unidad bíblica, de la continuidad entre Antiguo y Nuevo Testamento y de cómo las Escrituras (o al menos ciertos aspectos) necesitaban ser explicadas por una autoridad calificada, pues de otro modo podían conducir a la incertidumbre y al error.

\section{Los tres tiempos de Ildefonso de Toledo}

En la obra de Ildefonso tal interpretación, tanto la referencia a los seis días de la creación como a las seis edades del mundo, se halla ausente. En cambio, en De cognitione baptismi, el otrora abad de Agali propone otro tipo de esquema temporal centrado, esta vez, en la creación y devenir del hombre. La historia, según Ildefonso, había transcurrido a lo largo de tres épocas distintas: la primera de infelicidad, la 5o. Julián de Toledo, LA I, 1.

51. Julián de Toledo, LA I, 22-23: "Scriptum est enim: Qui uiuit in aeternum, creauit omnia simul". 
52. Ildefonso de Toledo, De cogn. bapt. XI.

53. Ildefonso de Toledo, De cogn. bapt. XI.

54. Ildefonso de Toledo, De cogn. bapt. XI.

55. Ildefonso de Toledo, De itin. des. II. segunda de no plena felicidad y la tercera de abundante felicidad. ${ }^{52}$ Desde esta perspectiva, el hombre había sido creado, post conditionem ceterarum rerum, en situación de felicidad a imagen y semejanza de Dios pero, una vez engañado por el diablo y expulsado del sitio en el que vivía feliz, fue sentenciado a conocer la muerte, tanto él como su entera descendencia. Se inicia la primera etapa de infelicidad. Luego, sobrevienen el segundo período, "quia data quidem lex est ad cognitionem Dei, sed perducere non potuit ad iustitiam Dei",53 y el tercero en el que "Christus est incunctanter ostensus, quando umbrae successit lux, incertis ueritas, figuris ostensio, occultis reuelatio, legi euangelium, timori seruorum gratia filiorum, et cunctis, quae adumbrauerat littera, manifestatio spiritalis gratissima et aperta". 54

Este esquema de tres etapas sucesivas (creación-caída-redención) que se corresponde además con tres momentos -antes de la ley, después de la ley y bajo el espíritu- es retomado también en De itinere deserti: "Primum, quando beatus conditus corruit deceptus. Secundo, quando in mediatoris morte extitit reparatus. Tertio, quando in redemptionis munere erit perenniter gloriosus". 55

La creación, por lo tanto, representaba el primer estadio de un camino lineal que llevaba al hombre, conducido por la Iglesia, a su restauración en la vida futura, esta última también considerada, en De cognitione baptismi, como una cuarta (y última) época de la más abundante felicidad. Notemos, en este sentido, que la perspectiva de Ildefonso, profundamente afectada por su pasado monástico, se concentra principalmente en la búsqueda espiritual del hombre, en el camino que este último debía transitar para alcanzar el estado de salvación. En el tratado del toledano, entonces, el devenir de la humanidad se observa desde una perspectiva espiritual: la creación, la caída y la redención última estructuran un itinerario que debía, según Ildefonso, enfocarse en la moral y en la ascesis cristiana para alcanzar finalmente ese último destino en la vida futura. Ildefonso, conectado con su compromiso monástico, ponderaba una cosmovisión destinada a guiar espiritualmente el progreso moral e interno del hombre cristiano.

\section{Conclusiones}

Hemos observado hasta aquí distintas matrices para pensar el devenir del hombre y del tiempo en relación a la encarnación y al presente: la primera isidoriana, y su variante julianea, la segunda, en cambio, elaborada por Ildefonso de Toledo. Estas formas diferentes de "contabilizar" las etapas o de concebir el itinerario que el hombre había de transitar antes del advenimiento del reino eterno de Dios, sin embargo, exhortaban a una espiritualización de la propia vida conforme al compromiso cristiano adquirido a través del bautismo.

Como un nuevo concilio de Nicea (325), el concilio III de Toledo, convocado por el rey Recaredo y celebrado en la urbs regia en el año 589, había condenado la herejía de Arrio ${ }^{56}$ hasta el momento practicada en el territorio peninsular. En directa continuidad con los primeros concilios ecuménicos -línea en la que los obispos de Hispania buscaban constantemente inscribirse- las actas de Toledo III repetían el credo nicenoconstantinopolitano en los que se afirmaba la teología de la creación elaborada por los antiguos Padres en el siglo IV.

Además de su presencia en la liturgia, el tópico de la creación aparece intensamente trabajado por los Padres visigodos, como hemos analizado a lo largo de estas páginas. Tanto Isidoro de Sevilla como Ildefonso y Julián de Toledo continúan, por una parte, el modelo interpretativo heredado de la tradición: se piensan a sí mismos como canales
56. Tol. III, 134-141: "Proinde sicut nec a Patre genitum sed ex nihilo titerunt, ita in honorem et in laudem fidem sanctam Nicaeni obseruo et honoro concilii, quam contra eundem rectae fidei pestem Arrium trecentorum decem et octo sancta episcopalis scripsit synodus" (La edición es de Martínez Díez y Rodríguez, 1992). 
autorizados de la sabiduría patrística. Empero, como también hemos observado, este papel desempeñado por la jerarquía eclesiástica no implicaba una mera reproducción de enunciados y razonamientos arrancados de los manuscritos de los antiguos, sino un trabajo activo de selección, organización y adaptación del contenido en torno de objetivos y preocupaciones específicos. A la hora de interpretar el texto sagrado los obispos de Hispania se apoyaron frecuentemente en la autoridad patrística: reformularon desarrollos exegéticos elaborados en otros contextos históricos, atravesados por intereses e inquietudes teológicas diversas y dirigidos a destinatarios heterogéneos.

Al ser despojados de sus marcos originales, estos enunciados se cargaron de nuevos sentidos y preocupaciones propias del nuevo escenario en el que se inscribían. Por lo tanto, si bien la transmisión del saber patrístico era un fin en sí mismo -considerado fundamental para la formación del clero- la selección, trabajo y adaptación del contenido se vinculaba con necesidades concretas del escenario visigodo del siglo VII. Es en este sentido que los obispos desempeñaron un papel principal en la transmisión del saber, mas orientada a unos fines específicos que emanaban de la sociedad en la que vivían y en la que ejercían sus funciones como líderes espirituales de la Iglesia católica. Educar al clero en la tradición bíblica y patrística constituyó una de las preocupaciones centrales del período, pues era necesario contar con prelados preparados para formar a las comunidades cristianas en la verdadera doctrina, capaces de reconocer creencias y prácticas contrarias a la fe y atender las inquietudes que podían presentarse diariamente en cada iglesia y en cada diócesis en particular.

Ahora bien, con la creación había comenzado también el principio del fin; era el punto de partida que inauguraba la entrada del hombre en la historia de la salvación. Tanto Isidoro como Julián utilizaron en sus obras el esquema de las seis edades heredado de Agustín. Mientras que el segundo seguía de cerca al santo de Hipona, Isidoro encaraba en su Crónica algunas modificaciones respecto de su predecesor. Como anotamos, una de las más significativas había sido la iniciativa del hispalense en situar el comienzo de la primera edad en la creación, inscribiendo al reino visigodo de Toledo en el plan providencial de la historia sagrada. Esta última comenzaba con el relato de los seis días descrito en el primer libro del Pentateuco. En cambio, Ildefonso ponderaba una periodización segmentada en tres etapas diferenciadas que el hombre debía transitar para llegar al estado último de felicidad eterna: la creación, la caída y la redención.

En suma, se advierte, por un lado, el deseo de continuar la teología patrística, aquella que afirmaba la existencia de un solo Dios omnipotente, creador de todas las cosas visibles e invisibles, sin intermediario ni materia preexistente. Estos interrogantes, recogidos por los obispos visigodos en sus obras, se vincularon, como vimos, directamente con la enseñanza y la corrección de posturas erróneas afirmando al obispo como el referente principal en materia bíblica, responsable de transmitir el verdadero conocimiento, decidir cuál enunciado se consideraba ortodoxo y cuál no. Esta condición de canal autorizado de la revelación divina definía, además, los contenidos que debían ser conocidos, los libros bíblicos que debían ser consultados y los interrogantes que debían ser atendidos. En última instancia, los tratados elaborados por los obispos, junto con sus sermones y homilías, eran en ocasiones las únicas vías de acceso a la Palabra. En este sentido, enseñar la creación, y los interrogantes que emanaban principalmente del relato concentrado en el Génesis, era de fundamental importancia, pues de allí se desprendían cuestiones esenciales del dogma sobre las cuales debía construirse el edificio de la fe. Preparar a los conductores que debían guiar al pueblo godo en su nuevo papel abrazado plenamente a partir de 589, constituyó la misión de los obispos visigodos, interesados en hacer de Hispania la representante de la ortodoxia más prominente del período y de cada comunidad su bastión más firme e inquebrantable. 


\section{Notas}

14 De acuerdo con Aldama (de Aldama, 1936: 62), dos indicaciones de carácter histórico habrían servido para determinar la redacción doble de esta obra: en la primera versión el arco temporal se extiende hasta el reinado de Sisebuto ("Fiunt igitur ab exordio mundi usque in eram praesentem, hoc est in anno quinto imperatoris Eraclii et quarto religiosissimi principis Sisebuti...” [Chron. I, 417]), mientras que en la segunda se prolonga al de Suinthila ("Fiunt igitur ab exordio mundi usque in praesentem eram DCLXIIII, hoc est in anno sexto decimo imperii Eraclii et quinto regiliosissimi principis Suinthilani..." [Chron. II, 417]). (En página 50.)

25 De acuerdo con Rodríguez Alonso, en esta interpretación Isidoro “recurre a la autoridad del profeta Ezequiel: et magis de Ezechiele propheta id colligentes. La identificación de los godos con la descendencia de los hijos de Jafet está avalada por una tradición que Isidoro se cuida bien de hacer notar, al repetir un pasaje de Jerónimo del que elimina el carácter de duda que ofrece respecto a dicha identificación" (Rodríguez Alonso, 1975: 32). En este sentido, podemos afirmar que apelar al procedimiento etimológico constituía también una forma de acreditar su interpretación en tanto correcta y verdadera. Agrega más adelante el autor: "El entronque del pueblo godo con los pueblos bíblicos tiene como objeto primordial el dar un prestigio y una justificación al triunfo de los bárbaros, y todo ello es fruto de una tentativa cristiana por crear una nueva visión histórica y una nueva comprensión de la historia" (Rodríguez Alonso, 1975: 33). (En página 51.)

40 Isidoro de Sevilla, Exp. II, 192-204: “Sex diebus consummauit deus omnia opera sua et septimo requieuit. Sex aetatibus humanum genus in hoc saeculo per successions temporum dei opera insigniunt. Quarum prima est ab Adam usque ad Noe, secunda a Noe usque ad Abraham, tertia ab Abraham usque ad Dauid, quarta a Dauid usque ad transmigrationem in Babylonia, quinta deinde usque ad humilem aduentum domini nostri lesu Christi, sexta, quae nunc agitur, usquequo mundus finiatur, donec excelsus ueniat ad iudicium. Septima uero intellegitur in requie sanctorum, quae scilicet uesperam non habet, quia eam iam nullus terminus claudet". Si bien la principal fuente de Isidoro en este punto es Agustín de Hipona (C. Faust., 12, 8), antecedentes del modelo narrativo de las seis edades del mundo pueden encontrarse también en la Crónica de Eusebio. (En página 53.) 


\section{Bibliografía}

" Gregorio Magno, Moralia in lob, en Adriaen M. (ed.), S. Gregorii Magni. Moralia in lob (CCSL 143, 143A, 143B), Brepols, Turnhout, 1985.

"Ildefonso de Toledo, De cognitione baptismi/ De itinere deserti, en V. Yarza Urquiola (ed.), Ildefonsi Toletani episcopi De uirginitate sanctae Mariae, De cognitione baptismi - De itinere deserti, De uiris illustribus (CCSL 114A), Brepols, Turnhout, 2007.

"Isidoro de Sevilla, Chronica, en J.C. Martín (ed.), Isidorus Hispalensis Chronica (CCSL 112), Brepols, Turnhout, 2003.

"Isidoro de Sevilla, Historia Gothorum, en C. Rodríguez Alonso (ed. y trad.), Las Historias de los godos, vándalos y suevos de Isidoro de Sevilla, León, 1975.

"Isidoro de Sevilla, Quaestiones in Vetus testamentum, en M. Gorman (ed.), Expositio in Vetus Testamentum. Genesis, Herder, Freiburg, 2009.

» Isidoro de Sevilla, Sententiae, en P. Cazier (ed.), Isidorus Hispalensis Sententiae (CCSL 111), Brepols, Turnhout, 1998.

» Julián de Toledo, Liber Anticimen, en J.C. Martín (ed.), Iuliani Toletani episcopi Opera II (CCSL 115B), Brepols, Turnhout, 2014.

" Martínez Díez G. y Rodríguez F. (eds.), La colección canónica hispana. V. Concilios hispanos, segunda parte, CSIC, Madrid, 1992.

\section{Estudios críticos}

» de Aldama J.A. (1936). "Indicaciones sobre la cronología de las obras de S. Isidoro", en Miscellanea Isidoriana, Roma, Universidad Gregoriana, pp. 57-89.

" Barney S.A., Lewis W.J., Beach J.A. y Berghof O. (2006). The Etymologies of Isidore of SeviIle, Cambridge University Press, Cambridge.

" Bonfil R., Irshai O., Stroumsa G. y Talgam R. (eds.) (2012). Jews in Byzantium, Brill, Leiden.

》Brett M. (ed.) (2002). Ethnicity and the Bible, Brill, Leiden.

"Buell D. (2005). Why this New Race, Columbia University Press, Nueva York.

»Campos J. (1971). “El conocimiento del bautismo. El camino del desierto", en V. Blanco García y J. Campos (trads.), Santos Padres Españoles I. San Ildefonso de Toledo, BAC, Madrid.

" Chaieb M-L. (2011). “Irénée, une des premières synthèses sur la création”, en M-A. Vannier (ed.), La création chez les Pères, Berna, pp. 9-24.

"Corradini R. (2003). "The Rhetoric of Crisis. Computus and Liber annalis in Early NinthCentury Fulda", en R. Corradini, M. Diesenberger y H. Reimitz (eds.), The Construction of Communities in the Early Middle Ages. Texts, Resources and Artefacts, Leiden, pp. 269-321.

» Dagron G. (1996). Empereur et prêtre. Étude sur le "césaropapisme» byzantin, Gallimard, París.

"Elías de Tejada, F. (1960). "Ideas políticas y jurídicas de San Isidoro de Sevilla”, Revista general de legislación y jurisprudencia, 108, pp. 225-238. 
» Evans C., Lohr J. y Petersen D. (eds.) (2012). The Book of Genesis, Brill, Leiden.

» Fontaine, J. (2000). Isidore de Séville. Genèse et originalité de la culture hispanique au temps des Wisigoths, Brepols, Turnhout.

» Garrison M. (2000). "The Franks as the New Israel? Education from an Identity from Pippin to Charlemagne”, en Y. Hen y M. Innes (eds.), The Uses of the Past in the Early Middle Ages, Cambridge, pp. 114-161.

» Gertz J., Schmid K. y Witte M. (eds.) (2002). Abschied vom Jahwisten. Die Komposition des Hexateuch in der jüngsten Diskussion, De Gruyter, Berlín.

» Grypeou E. y Spurling H. (eds.) (2013). The Book of Genesis in Late Antiquity, Brill, Leiden.

» Haldon J. (1990). Byzantium in the Seventh Century, Cambridge University Press, Cambridge.

» Hamman A. (1968). “L'enseignement sur la création dans l’Antiquité chrétienne”, Revue des Sciences Religieuses, 42-1, pp. 1-23.

» Harris J. (2011). "The Bible and the Meaning of History in the Middle Ages", en S. Boynton y D. Reilly (eds.), The Practice of the Bible in the Middle Ages, Nueva York, pp. 84-104.

» Heydemann G. (2013). "Biblical Israel and the Christian gentes: Social Metaphors and the Language of Identity in Cassiodorus's Expositio psalmorum”, en W. Pohl y G. Heydemann (eds.), Strategies of Identification: Ethnicity and Religion in Early Medieval Europe, Turnhout, pp. 143-208.

» Heydemann G. y Pohl W. (2016). "The Rhetoric of Election: 1 Peter 2.9 and the Franks”, en R. Meens et al. (eds.), Religious Franks. Religion and Power in the Frankish Kingdoms: Studies in Honour of Mayke de Jong, Manchester, pp. 13-31.

» Hillgarth J.N. (1970). “Historiography in Visigothic Spain”, en XVII Settimana di studio del Centro italiano di studi sull'alto medioevo, Spoleto, pp. 261-311.

» Kannengiesser C. (2004). Handbook of Patristic Exegesis. 2 Vols, Brill, Leiden.

» Koon S. y Wood J. (2008). "The Chronica Maiora of Isidore of Seville”, E-Spania [en línea], 6. URL: http://e-spania.revues.org/15552; DOI: 10.400o/e-spania.15552.

» Lewis J. (1989). “The Days of Creation: an Historical Survey of Interpretation”, Journal of the Evangelical Theological Society, 32, pp. 433-455.

» Lieu J. (2004). Christian Identity in the Jewish and Graeco-Roman World, Oxford University Press, Oxford.

" Louth A. (2012). “The Fathers on Genesis”, en C. Evans, J. Lohr y D. Petersen (eds.), The Book of Genesis, Leiden, pp. 561-578.

» Markus R. A. (1970). Saeculum: History and Society in the Theology of St Augustine, Cambridge University Press, Cambridge.

» Marrou H.-l. (1950). L'ambivalence du temps de l'histoire chez saint Augustin, Institut d'études médiévales, Montreal.

" Martin C. (2008). "La notion de gens dans la péninsule ibérique des Vle-Vlle siècles: quelques interprétations”, en V. Gazeau, P. Bauduin, Y. Moderan (dirs.), Identité et ethnicité. Concepts, débats historiographiques, exemples (IIle-XIle siécle), Caen, pp. 75- 89.

» Martín J. C. (2001). “La “Crónica universal” de Isidoro de Sevilla: circunstancias históricas e ideológicas de su composición y traducción de la misma”, Iberia, IV, pp. 199-239.

» Martín J. C. (2011). “Los Antikeimena (CPL 1261) de Julián de Toledo (s. VII): ensayo de reconstrucción con traducción y elenco de las fuentes”, Helmantica, 62-187, pp. 7-242. 
"Merrills A. (2005). History and Geography in Late Antiquity, Cambridge University Press, Cambridge.

»Otten W. (2005). “Reading Creation: Early Medieval Views of Genesis and Plato's Timaeus", en G. van Kooten (ed.), The Creation of Heaven and Earth, Leiden, pp. 225-243.

» Powis Smith J.M. (1929). "The Chosen People”, American Journal of Semitic Languages and Literatures, 45-2, pp. 73-82.

" Reydellet M. (1970). "Les intentions idéologiques et politiques dans la Chronique d'Isidore de Séville", Mélanges d'archéologie et d'histoire, 82-1, pp. 363-400. URL: http:// www.persee.fr/doc/mefr_0223-4874_1970_num_82_1_7602.

» Teillet S. (1984). Des Goths à la nation gothique: les origines de l'idée de nation en Occident du Ve au VIle siècle, Belles Lettres, París.

》Vannier M-A. (ed.) (2011). La création chez les Pères, Peter Lang, Berna.

»Wood J. (2012).The Politics of Identity in Visigothic Spain, Brill, Leiden.

"Wood J. (2013). "Religiones and gentes in Isidore of Seville's Chronica maiora", en W. Pohl y G. Heydemann (eds.), Post-Roman Transitions: Christian and Barbarian Identities in the Early Medieval West, Turnhout, pp. 125-168. 
